\title{
A Study of Cooperative Strategies that Enhance Individual Mathematical Achievement Among College of Education Students in Ghana
}

\author{
Bosson-Amedenu Senyefia ${ }^{1,}$, , Teku Emmanuel ${ }^{2}$, Vivian Nimoh $^{3}$, Osei-Asibey Eunice ${ }^{1}$ \\ ${ }^{1}$ Department of Mathematical Sciences, University of Mines and Technology, Tarkwa, Ghana \\ ${ }^{2}$ Department of Mathematics and Information and Communications Technology, Berekum College of Education, Berekum, Bono Region, \\ Ghana \\ ${ }^{3}$ Department of Mathematics and Information and Communications Technology, Holy Child College of Education, Takoradi, Ghana
}

Email address:

senyefia@yahoo.com (Bosson-Amedenu S.), sbosson-amedenu@stu.umat.edu.gh (Bosson-Amedenu S.)

${ }^{*}$ Corresponding author

\section{To cite this article:}

Bosson-Amedenu Senyefia, Teku Emmanuel, Vivian Nimoh, Osei-Asibey Eunice. A Study of Cooperative Strategies that Enhance Individual Mathematical Achievement Among College of Education Students in Ghana. Teacher Education and Curriculum Studies. Vol. 6, No. 1, 2021, pp. 28-32. doi: 10.11648/j.tecs.20210601.16

Received: February 19, 2021; Accepted: March 18, 2021; Published: March 26, 2021

\begin{abstract}
Cooperative learning strategies have the tendency to enhance the academic strength of learners. In this paper, the independent variable, type of cooperative strategy, included three levels: Jig-Saw, Think-Pair-Share, and Brainstorming. The dependent variable was the students' individual mathematics achievement scores and the covariate was the students' group score when the cooperative strategy was used. A preliminary analysis that sought to assess the homogeneity-of-regression assumption indicated that the relationship between the covariate and the dependent variable did not differ significantly as a function of the independent variable, $\mathrm{F}(2,81)=.045, \mathrm{p}=.956$. Principal component analysis (PCA) was used to reduce the three covariates to one score factor for ANCOVA procedure. A significant relationship was found between academic achievement score with respect to a cooperative strategy used and the individual academic achievement scores, $\mathrm{F}(2,83)=$ $249.030, \mathrm{p}<.05$. About $86 \%$ of the total variance in individual mathematics achievement score was accounted for by the three levels of cooperative strategy controlling for the students' academic group scores. Jigsaw cooperative strategy (Mean: 3.4, SE: $0.068, \mathrm{p}<0.01)$ had the most impact on individual achievement in mathematics with students obtaining an average grade of $\mathrm{B}+$. The findings also showed from the PCA that the mathematics achievement scores of the group treated with Jig-Saw cooperative strategy explained most (about 39\%) of the total variance, followed by Think-Pair-share with the least being Brainstorming. Explained in another way, when students use Jig-saw learning strategy in Mathematics, their individual academic potentials are enhanced well than when Think-Pair-Share or Brainstorming is used. It is therefore recommended for Jig-saw strategy to be the preferred strategy for learning when mathematics teachers seek to improve deep learning and problem solving among students.
\end{abstract}

Keywords: Jig-Saw, Think-Pair-share, Brainstorming, Cooperative Strategies, ANCOVA, PCA

\section{Introduction}

Cooperative learning allows students to develop their critical thinking, analytical and communication skills among other skills which tend to promote active learning [1]. Mathematics teachers in their quest to improve learner performance and achievements in the field of mathematics have conducted a number of works in recent years that identified instructional strategies which tend to improve students' academic achievement in Mathematics [4-10]. However, little attention seems to have been paid to the role cooperative and collaborative learning strategies play in 
learning of Mathematics

Adams [11], used Jigsaw cooperative learning strategy to improve upon the academic achievement of Basic six pupils of Holy Child Practice Primary School in Ghana. A sample size of 40, which included 30 pupils and 10 teachers from the same institution, was used. The academic achievement of the pupils improved with the Jigsaw intervention. Cooperative learning strategies have been proven to improve both group and individual academic achievement of students in Mathematics. Retnowati et al., [2], in their research also examined interactions between two cooperative strategies with 234 Grade-7 Indonesian students. The results indicated that while cooperative learning was beneficial when learning under problem solving conditions.

Olanrewaju et al., [3], sought to determine the effect of use of Jigsaw cooperative approach in the mathematical achievement of secondary school students. A sample of 87 students which comprised of 43 males and 44 females from two randomly selected schools in Nigeria was used. ANCOVA was performed and findings showed that a statistically significant difference between the mean achievement of students taught with Jigsaw cooperative strategy and those taught with conventional method.

\section{Purpose of the Study}

The purpose of this study was to determine the effect of co-operative learning strategies such as Jigsaw, Think-pairshare and brainstorming on the mathematics achievement of College of Education students in Ghana.

\section{Objectives of the Study}

Determine the mean achievement score of students in Mathematics who solved mathematics problems with Jigsaw, Think-pair-share and brainstorming cooperative learning strategies.

Determine the cooperative strategy that explains most of the total variance in the academic performance of the students in mathematics.

\section{Research Questions}

What is the mean achievement score of students in Mathematics who solved mathematics problems with Jigsaw, Think-pair-share and brainstorming cooperative learning strategies?

What is the cooperative strategy that explains most of the total variance in the academic performance of the students in mathematics?

\section{Research Hypothesis}

$\mathrm{H}_{\mathrm{ol}}$ : There is no significant difference between the mathematics achievement of College of Education students who used Jigsaw, Think-pair-share and brainstorming cooperative learning strategies to solve the given problem.

\section{Method}

Two hundred and fifty-two (252) randomly selected students were randomly assigned to 3 groups (84 students per group) which were treated with Jig-Saw, Think-pair-share, and Brainstorming Cooperative strategies after posing a problem (the problem was directly related to a just ended lecture). Students are allowed in their specific groups to carry-out the assignment using the specified cooperative strategy. Covariates such as group scores from the use of three cooperative approaches Jig-Saw, Think-Pair-Share and Brainstorming were the main control variables. Principal component analysis (PCA) was used to reduce the three covariates to one score factor for ANCOVA procedure. To ensure accurate measurement of covariates, with the aim of maximizing their capacity to depict noise variance in the response variable; ANCOVA was employed to decrease the error variance through removing the variance due to the group achievement score (with cooperative strategy group score as covariate) and the dependent variable (individual achievement score) which is the score of a particular student's achievement in an individual test. In effect, means of covariates are adjusted by ANCOVA procedure, leading to the adjustment of the means of the dependent variable (individual achievement in mathematics). Main effects and interactions were assessed on scores of the dependent variable after the dependent variable has been adjusted for by its relationship with the three Covariates. The dependent variable was Interval dependent.

The individual and group scores of the students were in the form of grades and so were coded for the purpose of the analysis.

Table 1. Grades and their assigned Weights.

\begin{tabular}{ll}
\hline GRADE & Weight \\
\hline A & 4 \\
B + & 3.5 \\
B & 3 \\
C + & 2.5 \\
C & 2 \\
D + & 1.5 \\
D & 1 \\
\hline
\end{tabular}

\section{ANCOVA}

When observed scores of covariates are unadjusted for, distortion resulting from these measurement errors may affect mean effects and significant tests. ANCOVA is very appropriate for reducing the noise variance that is not related to a specified group thereby maximizing their capacity to depict the evaluated relationship between group and response variable [12].

Think-pair-share Procedure

In this strategy, students were allowed to think to themselves on the exercise provided, first on their own to reach consensus and share with other peers and then the entire class. Students express their opinions and exhibit inductive and deductive reasoning which tend to enhance their participation and involvement in finding solution to the given problem. 
Have students sit in teams of 4 ; have them number them from 1 to 4 .

Pose the problem to be solved.

Grant students 'think time' to THINK of their own answer.

Use student numbers as a means to announce discussion partners.

Allow students to PAIR with their partner to discuss the solution to the given problem

Lastly, randomly select few students to SHARE their ideas with the entire class [13].

Jig Saw procedure

The teacher assigns an exercise for which certain responses are to be elicited. Team members become "Experts", and they master a critical section of the work to be completed.

a. A "home" group for each class member is formed. Each participant of a home group picks or is assigned a part of the exercise to be mastered. Each aspect must be understandable information that makes no reference to any other aspect.

b. In their focus groups, students complete the needed work for their area of expertise.

c. The focus groups now split up where the experts go back to their home groups to teach other group members what they know.

d. To end with, the group then utilizes the information to complete the required work. Every member of each group is tested independently to ascertain total content mastery [13-14].

Brainstorming procedure

A problem is posed to the students to find answers to.

Informal cooperative learning groups are usually formed

Each team generates strategies to solve the given problem

The strategies are written down, irrespective of their simplicity, complexity, or practicality.

The teams regroup into the larger class where a representative lists the strategies on the board, reported by each team. The Teacher with the teams will reach a consensus on whether duplicates should be recorded.

The Teacher must provide or lead the class to determine if listed strategies need to be retained or discarded.

The remaining strategies are then applied to solve the given problem [15].

Table 2. Levene's test of homogeneity of variance.

\begin{tabular}{llll}
\hline LeveneStatistic & df1 & df2 & Sig. \\
\hline .834 & 2 & 84 & .438 \\
\hline
\end{tabular}

The Levene's test of homogeneity of variance showed a non-significant result $(\mathrm{p}>0.05)$. The homogeneity of variance assumption is not violated in this case as evidenced by $\mathrm{F}(2$, $84)=.834, \mathrm{p}=.438$. That is, $\mathrm{p}(.438)>\alpha(.05)$.

Table 3. Tests of Between-Subjects Effects Without Covariate Inclusion.

\begin{tabular}{lllllll}
\hline \multicolumn{2}{l}{ Dependent Variable:GroupASS } & & & & & \\
\hline Source & Type III Sum of Squares & df & Mean Square & F & Sig. & Partial Eta Squared \\
\hline Corrected Model & $78.920^{\mathrm{a}}$ & 2 & 39.460 & 264.927 & .000 & .863 \\
Intercept & 334.247 & 1 & 334.247 & 2244.090 & .000 & .964 \\
CAT & 78.920 & 2 & 39.460 & 264.927 & .000 & .863 \\
Error & 12.511 & 84 & .149 & & & \\
Total & 528.500 & 87 & & & & \\
Corrected Total & 91.431 & 86 & & & & \\
\hline
\end{tabular}

a. $\mathrm{R}$ Squared $=.863$ (Adjusted R Squared $=.860$ )

Table 2 shows the main effect of cooperative strategy with $\mathrm{F}$ value of 264.927; statistically significant at 0.00 and Eta squared value of 0.863 . In effect, approximately $86 \%$ of the variability of Mathematical achievement is accounted for by the independent variable (cooperative strategy) as indicated by the effect size.

The group source (CAT) evaluates the null hypothesis that the population adjusted means are equal. The results of the analysis indicate that this hypothesis should be rejected, $\mathrm{F}(2$, $84)=264.927, p<.001$. The test assesses the differences among the adjusted means for the three groups, which are reported in the Estimated Marginal Means box as 1.170 (Brainstorming), 1.639 (Think-pair-share), and 3.412 (Jigsaw).

Table 4. Principal Component Analysis (Total Variance Explained).

\begin{tabular}{lllllc}
\hline \multirow{2}{*}{ Component } & \multicolumn{2}{l}{ Initial Eigenvalues } & \multicolumn{2}{c}{ Extraction Sums of Squared Loadings } \\
\cline { 2 - 6 } & Total & \% of Variance & Cumulative \% & Total & \% of Variance \\
\hline 1 & 1.156 & 38.541 & 38.541 & 1.156 & 38.541 \\
2 & 1.009 & 33.621 & 72.162 & & 38.541 \\
3 & .835 & 27.838 & 100.000 & & \\
\hline
\end{tabular}

Extraction Method: Principal Component Analysis.

Principal component analysis was used to reduce the covariates to one score factor for ANCOVA procedure. The resulting factor score is better indicator than the individual covariates. 
Table 5. Tests of Between-Subjects Effects (Homogeneity of regression assumption).

\begin{tabular}{|c|c|c|c|c|c|c|}
\hline \multicolumn{7}{|c|}{ Dependent Variable: Group ASS } \\
\hline Source & Type III Sum of Squares & df & Mean Square & $\mathbf{F}$ & Sig. & Partial Eta Squared \\
\hline Corrected Model & $78.934^{\mathrm{a}}$ & 5 & 15.787 & 102.319 & .000 & .863 \\
\hline Intercept & 316.527 & 1 & 316.527 & 2051.514 & .000 & .962 \\
\hline COLAFACTOR & .001 & 1 & .001 & .009 & .925 & .000 \\
\hline CAT $*$ COLAFACTOR & .014 & 2 & .007 & .045 & .956 & .001 \\
\hline Error & 12.497 & 81 & .154 & & & \\
\hline Corrected Total & 91.431 & 86 & & & & \\
\hline
\end{tabular}

a. R Squared $=.863$ (Adjusted R Squared $=.855$ )

The result shows a non-significant (or no) interaction between the factor (independent variable) and covariate (differences on the response variable among groups vary as a function of the covariate in prediction of the response variable; so, the assumption of homogeneity of regression slopes has been met. This test assures that the gradients of the regression lines of covariates with respect to the dependent variable are parallel; a condition that makes the adjusted mean to be obtained from ANCOVA reasonable. Our results suggest that the interaction is not significant, $\mathrm{F}(2,81)=.045$, $\mathrm{p}=.956$. Based on this finding, we can proceed with our ANCOVA analysis.

Table 6. ANCOVA OUTPUT.

\begin{tabular}{lllllll}
\hline \multicolumn{2}{l}{ Tests of Between-Subjects Effects } \\
\hline \multicolumn{1}{l}{ Dependent Variable: Group ASS } & & & & & \\
\hline Source & Type III Sum of Squares & df & Mean Square & F & Sig. & Partial Eta Squared \\
\hline Corrected Model & $78.920^{\mathrm{a}}$ & 3 & 26.307 & 174.516 & .000 & .863 \\
Intercept & 333.967 & 1 & 333.967 & 2215.516 & .000 & .964 \\
COLAFACTOR & $2.054 \mathrm{E}-6$ & 1 & $2.054 \mathrm{E}-6$ & .000 & .997 & .000 \\
CAT & 75.078 & 2 & 37.539 & 249.030 & .000 & .857 \\
Error & 12.511 & 83 & .151 & & & \\
Total & 528.500 & 87 & & & & \\
Corrected Total & 91.431 & 86 & & & & \\
\hline
\end{tabular}

a. R Squared $=.863$ (Adjusted R Squared $=.858$ )

The output indicates that a significant relationship exists between academic achievement in cooperative strategy used and the individual academic achievement, $F(2,83)=$ $249.030, p<.05$. Looking first at the significance values, it is clear that the covariate (ie. group score on Jig-Saw approach) had significantly influenced the dependent variable (i.e. Individual Achievement), evidenced by $\mathrm{p}<0.05$.

Therefore, performance in the cooperative strategy (JigSaw) had a significantv influence on the Individual mathematical achievement score.

Table 7. Adjusted Mean After ANCOVA.

\begin{tabular}{lllll}
\hline \multirow{2}{*}{ CAT } & \multirow{2}{*}{ Mean } & \multirow{2}{*}{ Std. Error } & \multicolumn{2}{c}{$\mathbf{9 5 \%}$ Confidence Interval } \\
\cline { 4 - 5 } & & & Lower Bound & Upper Bound \\
\hline .00 & $1.176^{\mathrm{a}}$ & .095 & .988 & 1.364 \\
1.00 & $1.639^{\mathrm{a}}$ & .065 & 1.509 & 1.768 \\
2.00 & $3.412^{\mathrm{a}}$ & .068 & 3.277 & 3.546 \\
\hline
\end{tabular}

a. Covariates appearing in the model are evaluated at the following values: REGR factor score 1 for analysis $1=.0000000$.

The adjusted mean (unbiased mean) accounting for the differences in the effect of the covariates of the Jig-Saw (Mean: 3.4, SE: 0.068), Think-Pair-Share (Mean: 1.6, SE: 0.065), and Brainstorming (Mean: 1.2, SE: 0.095), Cooperative approaches which is statistically significant. This means that cooperative approaches have significant effect on individual achievement. Jigsaw strategy cooperative strategy had the most impact on individual achievement in mathematics with the students obtaining an average grade of $\mathrm{B}+$.

\section{Conclusion}

This study set out to evaluate the impact of specific cooperative learning strategies on individual academic success in Mathematics. From the results, in terms of groups scores, students treated with Jig-Saw cooperative strategy outperformed those treated with Think-Pair-Share and Brainstorming. Again, individual students who used Jigsaw strategy outperformed individual students from the other two strategies when a follow-up test was conducted. This can be explained by the deep learning attribute associated with Jigsaw cooperative learning strategy. These outcomes corroborate the findings of Adams (2013) and Olanrewaju (2018).

\section{Recommendation}

It is recommended for Jig-saw strategy to be the preferred strategy for learning when mathematics teachers seek to improve deep learning and problem solving among students. 


\section{References}

[1] Sofroniou, A.; Poutos, K. Investigating the Effectiveness of Group Work in Mathematics. Educ. Sci. 2016, 6, 30. https://doi.org/10.3390/educsci603003.

[2] Retnowati E., Ayres P., and Sweller J., (2016), Can Cooperative Learning Improve the Effectiveness of Worked Examples in Learning Mathematics? University of New South Wales, Journal of Educational Psychology 2017, Vol. 109, No. $5,666-679$.

[3] Olanrewaju S., Anaduaka U.S, Olaoye A. E, (2016), Effect Of Jigsaw Instructional Strategy On Mathematics, Achievement Of Secondary School Students.

[4] Bosson-Amedenu S. (2017), Predictive Validity of Mathematics Mock Examination Results of Senior and Junior High School Students' Performance in WASSCE and BECE in Ghana, Asian Research Journal of Mathematics 3(4): 1-8, 2017; Article no. ARJOM. 32328 ISSN: 2456-477X SCIENCEDOMAIN international.

[5] Osei-Asibey E., Kusi P, Nimoh V., and Bosson-Amedenu S.(2020), Evaluation of Assessment Strategies Used by Basic School Teachers in Ghana: The Case of Assessment for Learning, Journal of Education, Society and Behavioural Science 33(4): 58-66, 2020; Article no. JESBS. 57218 ISSN: 2456-981X.

[6] Bosson-Amedenu S., (2017), Archbishop Porter Girls' Senior High School Students' Perception of Difficult Concepts in Senior High School Further Mathematics Curriculum in Ghana, Asian Research Journal of Mathematics 4(3): 1-14, 2017; Article no. ARJOM. 32331 ISSN: 2456-477X.

[7] Bosson-Amedenu S. (2017), Remedial Students' Perception of Difficult Concepts in Senior High School Core Mathematics Curriculum in Ghana, Asian Research Journal of Mathematics 3(3): 1-13, 2017; Article no. ARJOM. 32330 ISSN: 2456$477 \mathrm{X}$.
[8] Bosson-Amedenu S.,(2018), Effect of Use of WAEC Syllabus on the Mathematical Achievement of WASSCE Candidates in Ghana, Asian Research Journal of Arts \& Social Sciences 6(4): 1-8, 2018; Article no. ARJASS. 34695 ISSN: 24564761 .

[9] Bosson-Amedenu S., (2017), Remedial Students' Perception of Difficult Concepts in Senior High School Core Mathematics Curriculum in Ghana, Asian Research Journal of Mathematics 3(3): 1-13, 2017; Article no. ARJOM. 32330 ISSN: 2456-477X.

[10] Bosson-Amedenu S.*, Osei-Asibey E., and Otoo H., (2020), Factor Analysis Model for Diagnostic Assessment and Instructional Approaches in Ghana's New Curriculum: The Case of Differentiation, Scaffolding and Inclusion Archives of Current Research International 20(4): 1-16, 2020; Article no. ACRI. 57232 ISSN: 2454-7077.

[11] Adams F. H (2013), Using Jigsaw Technique As An Effective Way Of Promoting Co-Operative Learning Among Primary Six Pupils In Fijai.

[12] Gregory A. M, Chapman J. P. (2001), Misunderstanding Analysis of Covariance, Journal of Abnormal Psychology 2001, Vol. 110, No. 1, 40-48.

[13] Davidson, N., and Worsham, T. (Eds.) (1992). Enhancing thinking through cooperative learning. New York: Teachers College Press.

[14] Clarke, J. (1994). Pieces of the puzzle:The jigsaw method. In. S. Sharan (Ed.), Handbook of cooperative learning methods (pp. 34-50). West Port, CN: Greenwood Press.

[15] Bonwell, C. C. \&Eison, J. A. (1991). Active learning: Creating excitement in the classroom (ASHE-ERIC Higher Education Report 1). Washington, DC: The George Washington University. 